

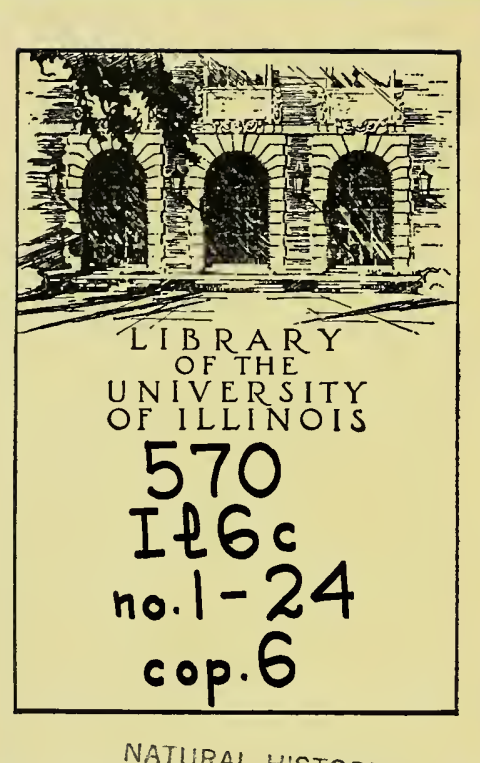



Digitized by the Internet Archive in 2011 with funding from

University of Illinois Urbana-Champaign 
• 



\section{The More Important Insecticides and Repellents}

Insecticides are of three principal kinds-stomach poisons, contact poisons, and fumigants. Stomach poisons are effective when swallowed, and are used against insects which bite and chew their food, such as grasshoppers, cutworms, army-worms, and beetles. Contact poisons kill when placed in contact with the outer surface of the insect, and are used against tlose kinds which feed by piercing the plant or animal and sucking fluids through a tubular beak. Tree-hoppers, plant-lice, certain flies, and mosquitoes are examples. Fumigants are gases or vapors which kill by penetrating the breathing apparatus of the insects exposed to them. They are used against injurious insects which are so situated that they can not be reached effectively by stomach or contact poisons, such as certain greenhouse insects and those infesting houses or feeding upon stored grains and cereal foods.

\section{STOMACH POISONS}

\section{Arsenate of LEad.}

Arsenate of lead is the most widely used, and, for most purposes, is the best of the common stomach poisons. It has the advantage that it mixes readily with water, that it is not likely to burn the foliage, and that it sticks well to the plants after drying. It is on the market in two forms-a thick paste resembling white lead, and a dry white powder. Either form may be mixed with water and applied as a spray, or the powder may be used as a dust. The powder is about twice as strong as the paste, weight for weight, and, as it will keep much better, it is the best form for the small grower to buy. If the paste is used, it should always be mixed with a little water before putting it in the sprayer. Where one application is to be made for the control of both insects and diseases, arsenate of lead has the additional advantage that it can be used with dilute lime-sulfur; Bordeaux mixture, or self-boiled lime-sulfur, and also with the strong nicotine solutions. The paste

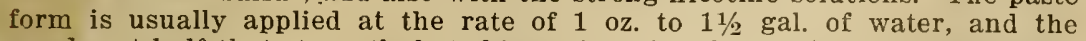
powder at half that strength, but this varies with the insects to be controlled. The present price of the paste is about 50 cents a pound for single pounds, and less than half that if larger amounts are purchased. It should always be remembered that mixtures of arsenate of lead must be constantly agitated in the sprayer while being applied.

\section{Paris Green}

This coarse, green powder, composed of arsenite of copper, was the most common insecticide used up to a few years ago, but it has now been largely replaced by arsenate of lead. It is still used extensively, especially for spraying potatoes. It is much more likely than arsenate of lead to burn the foliage, as there is always a considerable amount of soluble arsenic present in the powder. This can be prevented, to some extent, by adding fresh lime 
to the mixture at the rate of two pounds of lime to each pound of Paris green. It should never be used without the lime on plants having a tender foilage. Paris green does not stick well to the plants, and a rain shortly after spray. ing will wash most of the poison from the leaves. It lias the advantage of a slightly quicker effect on most insects than arsenate of lead. In mixing, the Paris green should be thoroughly wet with a small amount of water before it is put into the sprayer, and should be kept well stirred while being applied. It is commonly used at the rate of $1 \mathrm{oz}$. to 6 gal. of water, but this amount will vary with the insects to be treated. The present price is from 75 cents to $\$ 1$ per pound. Paris green may be combined with Bordeaux mixture, but can not safely be used with dilute lime-sulfur, self-boiled lime-sulfur, or nicotine solutions.

Arsenate of Limè or Calcium Arsenate

This insecticide is on the market in the form of a paste and a very fine white powder. It has some of the advantages of arsenate of lead, but it is not as adhesive, and is much more likely to burn the foliage. It is cheaper, but somewhat slower in effect. It should be used at the rate of about $1 \mathrm{oz}$. of calcium arsenate, and $1 \mathrm{lb}$. of hydrated lime to 4 gal. of water, depending on the insect to be destroyed. It can be bought in single pounds for about 40 cents for the paste or 60 cents for the powder, the powder having twice the strength of the paste, weight for weight.

\section{Stomach Poisons of Little Value}

\section{Arsenate of Zinc}

This powder has been used effectively in some parts of California, but in other parts of the country having a markedly different climate and soil it is very likely to burn the foliage severely.

\section{LoNdon Purple}

This is a waste product from the manufacture of dyes, and is very likely to burn the foliage severely unless mixed with large amounts of fresh lime. It is less effective than arsenate of lead or Paris green. The price is about 25 cents a pound. It should be used at the same strengths as Paris green.

\section{HELLEBORE}

This is the powdered root of the white hellebore. It is a fairly effective poison for insects when it is fresh, but it loses its strength very rapidly and for this reason should always be kept in tight containers. It is used either as a dry powder mixed with equal parts of air-slaked lime or gypsum, or as a spray at the rate of $1 \mathrm{oz}$. to 2 qts. of water. The present price is from 75 cents to $\$ 1$ a pound.

There are a number of insecticides on the market under such trade names as Slug-shot, Bug-death, Black-death, Sure-death, etc. These contain some substances of insecticidal value, but are usually mixed with large quantities of zinc and iron oxids, gypsum, etc. When their real value as insecticides is considered, they are much more expensive than arsenate of lead or Paris green.

\section{Poisoned BaIts}

Certain chewing insects can be killed in greater numbers by the use of poisoned baits which attract them for considerable distances than by applying poisons to the plants on which they feed. Cutworms, army-worms, and grasshoppers are the commonest examples of these insects.

One of the best baits is made by mixing with 25 pounds of dry bran, 1 pound of Paris green or 2 pounds of powdered arsenate of lead, 6 oranges or lemons chopped fine, 2 quarts of low-grade "black strap" molasses and enough water to make a stiff mash. This bait should be scattered in the early evening over the infested areas.

For small amounts for garden use, mix 1 tablespoonful of Paris green or 2 of powdered arsenate of lead, 2 quarts of dry bran, $1 / 2$ cup of molasses, $1 / 4$ orange or lemon, and water to make a stiff mash. In gardens good results will be had by placing small amounts of the bait under pieces of board or shingles where the cutworms hide during the day. 


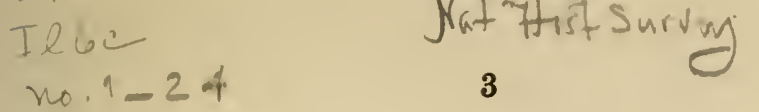

CONTACT INSECTICIDES

It must always be borne in mind that-this class of insecticides must be so applied as to come in direct contact with the body of the insect. Spraying or dusting plants with them in the absence of the insect is useless.

TOBACCO

Extracts of tobacco are the best sprays for killing plant-lice and other soft-bodied insects on plants with a tender foliage. The value of tobacco as an insecticide depends on the amount of nicotine it contains. This varies so greatly with the kind of tobacco that it is difficult to make a satisfactory home-made extract. A fairly effective extract may be made, however, by steeping $1 \mathrm{lb}$. of tobacco stems or sweepings in 1 gal. of water kept just below boiling, for about 3 hours. It is much more effective if $1 \mathrm{oz}$. of laundry soap is dissolved in each gallon.

There are several extracts of tobacco on the market for which the per cent. of nicotine is guaranteed, and these are much the best for general use. Most of these contain 40 per cent. of nicotine, and are used at the rate of 1 part of the tobacco extract in 600 to 1000 parts of water. When used alone, laundry soap at the rate of $1 \mathrm{oz}$. to the gallon should be dissolved in the mix. ture. If combined with dilute lime-sulfur or Bordeaux mixture, the soap should be omitted. The commercial extracts can be bought for about 75 cents a half pint, or $\$ 10.50$ a gallon. For small amounts of spray for garden work, lialf a tablespoonful may be put into each gallon of water with $1 \mathrm{oz}$. of laundry soap dissolved in the water.

Tobacco is also used as a contact poison in the form of finely ground dust made from tobacco stems. In this form it has considerable value for use on some insects.

\section{Kerosene Emulsion}

This is one of the oldest forms of contact insecticides. It has the advan. tage that it is cheap, and that the materials from which it is made are always readily obtainable. It should always be kept in mind, however, that it may burn the foliage severely if used on tender plants. It can be bought ready for use, but is generally made at home.

To make the emulsion, dissolve half a pound of laundry soap in 1 gal. of hot soft water and, while the water is still hot, add 2 gal. of kerosene (coal oil) that has been slightly warmed. Churn the water and oil together thoroughly for at least ten minutes, either by pumping it forcibly back into itself or by vigorously stirring with a bundle of twigs or broom. When finished, it should have the appearance and consistency of thick cream, and it can then be kept for some weeks if put in closed containers. This is the stock solution, and is diluted for use to form a 5 to 25 per cent. mixture (containing from 5 per cent. to 25 per cent. of kerosene), according to the plants to be sprayed.

For a 5 per cent. mixture, use 3 parts of stock emulsion to 37 parts of water; for a 10 per cent. mixture, use 3 parts to 17 of water; for 15 per cent., use 3 parts to $10 \frac{1 / 3}{3}$ parts of water.

For making a small amount of the emulsion for garden use, dissolve a 1-inch cube of laundry soap in $1 / 2$ pt. of hot soft water, add 1 pt. of kerosene, churn with an egg-beater, and keep sealed in a mason jar.

\section{LIME-SULFUR}

For the past ten years the lime-sulfur sprays have been the standard for controlling the San Jose scale and nearly all other scale insects occurring in the state. They have also proved very effective in controlling many fungus diseases, and during the last few years have largely replaced Bordeaux mixture as a summer spray in orchards.

The home-made lime-sulfur mixture is made by boiling together 12 to 15 lbs. of fresh lime (or $20 \mathrm{lbs}$. if hydrated lime is used) and $15 \mathrm{lbs}$. of the flour or flowers of sulfur. Place the lime in an iron kettle containing about 10 gal. of hot water, slake and stir in the sulfur, adding water to make about 15 gallons. Boil for one hour, stirring vigorously to prevent burning or caking of the materials. Strain, dilute to 50 gallons and spray at once, if 
possible. This mixture will cost, labor included, about 2 or 3 cents a gallon when ready to apply to the tree. It has the disadvantage of containing a large amount of sediment which causes trouble with the nozzles in spraying. There are many brands of lime-sulfur now on the market which are fully as effective as the home-made mixture; they are much more convenient to use, as they are free from sediment and require no preparation other than adding the proper amount of water; the cost is very little, if any, greater than the home-made mixture; and, as a rule, they will be found much more satisfactory. The commercial brands sell at from 20 to 25 cents a gallon in 50-gallon barrels. Most of them should be used at the rate of 1 gal. to 8 gal. of water for a spray against the San Jose scale, and 1 gal. to 40 gal. of water for summer spraying.

The mixtures of lime and sulfur are caustic and should be kept from the hands and face as much as possible. They should never be put into a copper tank, and the pump and hose should always be cleaned out immediately after they are used.

\section{Soluble OILS}

There are on the market a number of brands of strong oil-emulsions made from petroleum and vegetable oils, broken with some alkali, and known as soluble or miscible oils. They are mainly intended for use against the scale insects, and are effective at the proper strengths. They do not have the fungicidal properties of the lime-sulfur mixtures, and are more expensive, costing about 50 cents a gallon in 50-gallon barrels. For spraying against scale they are used at the rate of 1 gal. to 12 or 15 gal. of water. They do not have the caustic properties of the lime-sulfur mixtures, and are hence more easily handled. Their long-continued use may be dangerous to the health of the trees. Some of the more common brands are Scalecide, Orchard brand, and Target brand.

\section{Sodium Fluoride}

This substance is just coming into general use for destroying insects and mites infesting animals, and such household pests as ants and cockroaches. It is in the form of a very fine white powder, and can be bought for from 30 to 75 cents a pound. It is dusted dry into the hair or feathers of domestic animals or poultry or the hiding places of household insects, or used in solution for the same purpose. Judged by the results of experiments reported, it bids fair to become one of our most useful insecticides.

\section{Buhach, Pyrethrum, or Dalmatian Powder}

A powder made of the ground blossoms of a species of pyrethrum is commonly known by the above names. It is harmless to plants or animals, but has considerable value when fresh as a contact insecticide for some household insects. It can be burned to rid rooms of flies or mosquitoes, or used dry on plants or about the hiding places of insects. It is expensive when its value as an insecticide is considered. It should always be kept in tight cans, as it loses strength rapidly when exposed to the air.

\section{SOAPS}

Any good laundry soap, used at the rate of half a pound to 2 gal. of water, is fairly effective against plant-lice, but inferior to tobacco solutions. Whale-oil, fish-oil, and potash soft-soaps are much more effective than the hard soaps, and the solutions made from them will keep better, but they are likely to cause burning of the foliage of tender plants. These soaps are used at strengths of from $1 \mathrm{lb}$. to 5 to 7 gal. of water, and cost from 10 to 30 cents a pound, according to the amount purchased.

\section{FUMIGANTS}

\section{Carbon Disulphid (Bisulphid)}

Carbon disulphid is a nearly colorless, ill-smelling liquid that volatilizes very rapidly when exposed to the air at ordinary temperatures. The vapor from it, when mixed with air in certain proportions, is very explosive. This vapor is heavier than air, and hence tends to sink to the bottom of any 
container in which it is used. It is deadly to all forms of insect life if used in sufficient strength and is, on the whole, the best fumigant for treating grain in bins, foodstuffs, and clothing that can be placed in tight rooms or receptacles. Several points bearing on the efficiency of this gas have been overlooked untll recently, and this has been the cause of many of the failures in its use. It should never be used at temperatures below $60^{\circ}$ F., and the best results will be obtained at $75^{\circ}$ to $90^{\circ} \mathrm{F}$. Great care should be taken to have all bins, rooms, or containers to be fumigated as nearly air-tight as possible. The average grain bin is very far from air-tight. Where there is sure to be some leakage, the amount of carbon disulphid must be increased; but no attempt should be made to fumigate a room or bin that is very open. Under ordinary conditions, 1 pound of carbon disulphid should be used to each $100 \mathrm{cu}$. ft. of space. It may be applied directly to the grain, but better results will be obtained by wetting sacks with the liquid and placing them in the top layers of the grain. Small amounts of grain, seeds, and clothing may be fumigated in tight barrels by placing a gunny sack wet with half a cupful of the liquid over the contents and closing tightly for from twelve to twenty-four lours. Exposure to the gas at $1 \mathrm{lb}$. to $100 \mathrm{cu}$. ft. for twenty-four hours, will not lessen the germination of seeds. The vapor is also used to break up the nests of ants, for killing underground insects, and to destroy plant-lice on growing plants. The present price of the liquid is from 30 to 50 cents a pound. The inflammable nature of this vapor must always be kept in mind. Even the spark caused by striking a nail with a hammer or turning on an electric light may cause it to explode.

\section{Hydrocyanic Acid Gas}

This gas, which is one of the most poisonous known, is generated by combining water, commercial sulfuric acid, and sodium or potassium cyanide. Sodium cyanide is now most commonly used. This gas is the most efficient insecticide for many of the household and greenhouse insects, for some of the grain insects, and for insects on nursery stock. It does not have the penetrating power of carbon disulphid when applied to large masses of grain. It is not explosive, but is deadly to all forms of animal life. One full breath of it would render a man unconscious, and might prove fatal. It will not discolor wall-paper or fabrics.

Houses in which the gas is to be used should be made as nearly air-tight as possible, and so arranged that they can be ventilated from the outside after they are fumigated. A room which has been filled with it should never be entered until it has been thoroughly aired. If single rooms are to be fumigated, care should be taken that none of the gas can escape to the remainder of the house.

For household insects, asery toek, and grain insects, one-should use for each $100 \mathrm{cu}$. ft. of space:

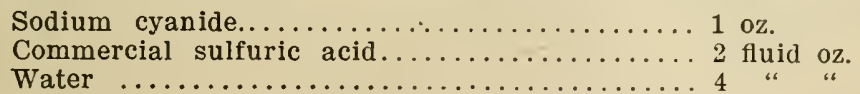

Place the water in a deep earthen or stoneware (never metal) container, add the acid slowly and, having everything ready to leave the room at once, drop in the cyanide loosely wrapped in paper - Close the room and keep it closed for at least one lour. Use more than one container if over 2 pounds of the cyanide is to be used. After fumigation is finished, the residue in the generator should be buried. The best results are generally obtained at temperatures between $60^{\circ}$ and $90^{\circ} \mathrm{F}$.

The amount used for greenhouse fumigation varies with the plants and insects to be treated, but is seldom over a half ounce to $1,000 \mathrm{cu}$. ft.

The present price of sodium cyanide is from 50 cents to $\$ 1$ a pound.

\section{HeAT}

Practically all insects are killed if exposed for any length of time to temperatures of from $120^{\circ}$ to $125^{\circ} \mathrm{F}$. Maintaining these temperatures for several hours has been found the best method for ridding flour-mills of 
insects. Those in small lots of seeds, dried foodstuffs, or clothing may be killed by heating to these temperatures. Seeds intended for planting should not be heated above $130^{\circ} \mathrm{F}$.

\section{Toвacco}

Tobacco dust or tobacco papers are often used for fumigating greenhouses, the fumes being generated by burning. The odor of these substances makes them unsuitable for use in houses.

\section{SULFUR}

Sulfur is sometimes burned in houses to rid them of insects, but it is not as effective as the substances mentioned above unless the fumes are very closely confined. It has also the disadvantage that the fumes discolor wallpaper and fabrics.

\section{Formaldehyde}

This substance, while very effective as a germicide, is nearly useless for killing insects, although sometimes recommended for this purpose.

\section{REPELLENTS}

Some substances having very little value as insecticides are of use in preventing insects from attacking plants and stored products. Among the most efficient of these is air-slaked lime, whicl is used extensively for dusting melons and cucumbers to prevent the attacks of the striped cucumber-beetle. This has also recently been used with considerable success in preventing injury to stored beans by the bean-weevil. Bordeaux mixture sprayed on the leaves of egg-plants and potatoes aids in preventing injury by flea-beetles. Crude carbolic acid and crude creosote have a very marked repellent effect on some insects.

For more detailed information in regard to the use or preparation of insecticides, apply to the Natural History Survey at Urbana, Illinois.

1231 W. Edwards St., Chief Field Entomologist.

Springfield, Ill.,

March 27, 1918.

Some of the manufacturers of insecticides:

Grasselli Chemical Co., Chicago, Ill.

Rex Spray Co., Omaha, Neb.

Sherwin-Williams Co., Cleveland, Ohio.

Thomsen Chemical Co., Baltimore, Md.

Corona Chemical Co., Milwaukee, Wis.

Dow Chemical Co., St. Joseph, Mich.

Kentucky Tobacco Products Co., Louisville, Ky.

B. G. Pratt Co., New York, N. Y.

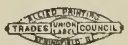

Schinepp \& Barnes, State Frinters

SPRINGFIELD, ILI.

1918. 




UNIVERSITY OF ILLINOIS-URBANA

570IL6C

CIRCULAR C006

1-24

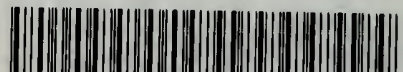
30112017541175 